\title{
Conceptualising Intensive Caring Activities: the Changing Lives of Families with Young Disabled Children
}

\author{
by Janice McLaughlin \\ University of Newcastle \\ Sociological Research Online, Volume 11, Issue 1, \\ < http://umw. socresonline.org.uk/11/1/mclaughlin.html> \\ doi:10.5153/sro. 1219
}

Received: 5 Jul 2005 Accepted: 13 Jan 2006 Published: 31 Mar 2006

\begin{abstract}
Feminists have put care on the sociological agenda. At times they have defined it as an activity that imprisons women, at other times they have seen it as a value that is marginalised in society and should be celebrated. In contrast disability writers view care as a category that pathologises those who are defined as its recipients and seek to avoid both the language of care and analysis of those who 'care for' disabled people, for example parents of disabled children. This paper argues that it is important to work with the concept of care and to explore the activities of parents. The contexts within which individuals are involved in caring activities frame and influence what is seen as care, how care is performed and received, how different roles and identities are read and how changes occur within caring activities and within the lives of those involved. Therefore exploring the social, cultural and political contexts within which care occurs is important to understanding its significance. Through discussion of a research project involving the parents of very young disabled children this paper argues that cultural stereotypes around disability within the medical model and within society confine the care made available to families where impairment is present. However, it goes on to argue that families challenge that containment through patterns of care they adopt and receive from others in similar positions to themselves and through seeing value and worth in their new lives and family form. The social and political dimensions to this transformation are examined in order to situate care and transformation at the societal rather than individual level.
\end{abstract}

\section{Keywords: Disability, Care, Family, Feminist Theory}

\section{Introduction}

1.1 Feminist sociologists have successfully argued that care, and women's role in the provision of it, is worth exploration. Work in the 1970s and the 1980s highlighted the labour involved in women's caring role (Finch and Groves 1983). Beginning in the 1980s, the ethics of care debate has challenged the trivialisation of women's caring role and asserted the significance of care involvement in the production of particular forms of subjectivity and moral frameworks (Gilligan 1993; Lister 1999; Sevenhuijsen 1998). Recent work has explored the cultural and social norms and discourses that inform and compel women to adopt caring responsibility and respectability (Skeggs 1997). However, feminist accounts of the significance of care have been criticised by others. Disability writers in particular have criticised feminists for being only concerned in the role and fate of the carer (Morris 1996; Sheldon 1999). For example, Skeggs proposes that 'the caring self is a dialogic production: a caring self cannot be produced without caring for others' (1997: 56), but within the text does little to explore the subject position or identity of the 'others' she speaks of. The result of this critique has been a reticence within disability studies to explore care (instead the talk is of assistance (Watson et.al. 2004)) and the lives and identities of those who care for disabled people.

1.2 This reticence to debate the significance of care has created a lack of engagement with, and even hostility towards, parents of disabled children. At times non-disabled parents of disabled children have been presented as part of the problem, anxious to talk of their own burden and side with professionals against the needs and interests of their children. This is not a useful situation and does little to help understand the significance of parental experiences of caring roles to the social position of disabled children. It is based on an assumption that there exists a binary opposition between all aspects of disabled and non-disabled people's experiences, ignoring the reality of the stigma, social deprivation and exclusion that non-disabled family members may face alongside their disabled relatives (Beresford et al 1996; Brett 2002; Dobson et al 2001; Murray and Penman 2000). 
1.3 Therefore, there is a need to explore the lives of parents of disabled children and to concentrate within this on the significance of the caring roles they perform. In particular it is important to examine how care is valued or disvalued, how contexts channel care towards particular actors and how barriers within society confine both care practices and those involved in care into a marginalised and secluded private sphere. Such work is beginning within recent accounts of the lives of parents of disabled children, which conceptualise the mutual construction of notions of impairment and disability and forms of parenting and family. By summarising this literature and then moving onto a discussion of research that has been undertaken with parents of very young disabled children ${ }^{[1]}$, the paper will explore the patterns of care parents are involved in. Such experiences challenge the privitisation of care and provide testimony to the lack of public responsibility to care. First, however, it is important to both make clear why disability writers have sought to exclude care from discussion of the lives of disabled people and why this position is limiting.

1.4 Before doing so it is important to clarify an important aspect of terminology. Feminist accounts of caring within the family commonly focus on mothers, a reaction to the reality that women continue to perform the majority of caring roles within it. However, this paper and the research it draws from are framed as studies of parenting. The reason for doing so is to allow space to consider how gender roles and cultural values position women and men differently within families and caring roles. Exploring how divisions of role occur and the significance of wider gender relations and processes in shaping them is best done by not excluding fathers from the onset.

\section{What's wrong with care?}

2.1 Historically within both medical literature and in real-world practice, disabled people have implicitly and explicitly been positioned as passive recipients of care enacted by omnipotent non-disabled professionals and burdened informal carers (Deeley 2000; Finkelstein 1996). 'Care' troubles disabled people, their representative organisations and disability studies scholars, for the following reasons. First, care is a term normally associated with a rehabilitation model of disability (Safilios-Rothschild 1970). Such a model emphasises individual adjustment to, or the remedying of, impairments and ignores the need for social environments to become more inclusive of different bodies and minds (Harris 2003). Medical care is seen as the alleviation of physical and mental suffering, while this in itself is not intrinsically wrong, it fails to challenge the medical model of tragedy and pathology that has embedded within it that through intervention impairment can be fixed, while anything else represents failure. Second, care sits within a charitable discourse, that brings with it notions of pity and optionality; which is that care is a benevolent gift the receiver should be grateful for and accept without question (Hughes 1999). As Lindemann argues, charitable care is 'something of an "extra" action; something not quite required' (2003: 507). Charitable caring for Hughes has 'mobilised the emotions invested in the tragic and the pitiful' (2002: 577). For Kittay care for people with high levels of dependency is constructed as charitable rather than a right and is therefore given 'out of a gratuitous kindness, a kindness they have no right to demand' (2002: 271). Third, there are concerns about the way that mainstream discussion of care appears to foreground the experiences of caregivers and masks the experiences of disabled people. This is demonstrated in relation to popular debate about the plight of 'child carers' (Morris 1996). Fourth, within disability studies itself there is resistance to exploring caring dynamics because such talk can become a form of 'sentimental biography' (Finkelstein 1996, Barnes 1998), which implies an unacceptable analytical turn away from the social conditions of disablement towards an individualistic preoccupation with medical care and practical details of impairment conditions.

2.2 While the problems disability writers identify within dominant discourses of care are correct, to walk away from engaging with it is not helpful. There is a need for conceptual engagement with care, in particular how it can be transformative. While Skeggs (1997) fails to examine care from the perspective of anyone but the carer, usefully she highlights how the contexts within which individuals are involved in caring activities frame and influence what is seen as care, how care is performed and received, how different roles and identities are read and how changes occur within caring activities and within the lives of those involved. Processes of both self-regulation and agency, within gendered boundaries, influence the patterns of care women enact and how they and others read it as part of their identity as women, mothers and workers. Therefore exploring the social, cultural and political contexts within which care occurs is important to understanding its significance. This is vital within debates about disability, it provides for a deeper appreciation of the significance of the support provided by carers and assistants for disabled people. It allows for exploration of the ways in which negative caring activities are influenced by cultural norms around disability and the ways in which politicised notions of disability inform caring practices that challenge such norms. Work exploring the lives of parents (primarily mothers) caring for disabled children is beginning to explore such processes. 
3.1 Initial work on parents of disabled children focused on the burden of care, highlighting, often from a psychological perspective, the toll that caring took on parents' lives and the various emotional 'failures' they experienced, for example denying the reality of disability (see McKeever and Miller (2004) for a useful summary of this literature). This literature was followed by social policy oriented accounts that highlighted institutional failure to provide care as the main cause of parents' distress and inability to cope (Dale 1996; Traustadottir 1991). More recently, work is appearing which highlights the transformative nature of the role that parents play and how mothers find new meaning for themselves and for and with their children.

3.2 An important aspect of understanding how parents come to know, love and understand their disabled child or children is within and via challenges to the medical and cultural discourses about disability that surround them. Landsman has identified four discursive influences on mothers' processes of understanding and interpreting their child (Landsman 2003: 1948-1949). The first is popular culture discourses from the media that frame disability as a personal tragedy that befalls both tragic children and equally tragic families. The second emerges from paediatric medical culture and constructs disability as an individual pathological condition; the third discourse is of heroic progress, the child who overcomes their disability to walk, talk or do well at school. Each of these narratives is based on a normalising ideology that assumes that to be disabled is to be less than human, as 'outside the range of human acceptability' (ibid: 1950). If disability is something to be overcome, to stay within it is to be doomed by a condition that frames the individual. The final discourse is the disability rights movement, which challenges the assumptions of the first three, by resituating the source of disability as a product of the failure of society to recognise those with impairments as having equal rights with others.

3.3 Families with disabled children experience greater incorporation of public judgements and discourses into their lives and definitions of them as a family unit. In the words of Kelly 'private and public are not separate domains but are interpenetrated' (2005:200). McKeever and Miller (2004) argue that in western society successful mothering is connected to 'accomplishment', that is the child whose 'future' is somehow guaranteed by the mothers' skill and expertise (what Hays (1996) calls 'intensive mothering'). Therefore, the narrative for mothers of disabled children is made more complicated, as the future is already read by others as no longer available. Parenting generally is under a heightened gaze through increased levels of medical advice and guidance on how to raise perfect children, the more this is emphasised and wished for, the more parents of disabled children and the children themselves are constructed as failures (James 1993).

Landsman (1999) argues that the increased use of medical technologies to screen out fetuses with congenital conditions and the growth of health promotion literature advocating particular health routines and behaviours prior to and during pregnancy, to reduce the risk of negative outcomes, is an important context through which mothers and children born with impairments are disvalued and judged by society.

3.4 Parents and children can face experiences of public judgement and scrutiny most acutely where there is a lack of clear diagnosis or visible disability that medically validates the child's behaviour (Green 2003). For example, Gray (2002) argues that parents of children with high functioning autism experience stigma due to interpretations of their children as simply naughty and them as poor parents. Parents must make sense of the interpretations being provided by medical and cultural views of disability, for them and for their children, and within this find their own sense making of their lives and their child. In such contexts parents seek to continue to assert the self-worth and value of their children, however different their futures will be. In various fronts, parents seek to retain a public space and value for their children, through deliberate claims to normalcy, without denying that their children are different (and in some ways positively different), parents seek ways to assert their very 'ordinariness' (Prout, Hays and Gelder 1999). In this way the psychological critique of parents who 'deny' the disability of their child is repositioned as a 'helpful strategy to emphasize the child's worth in a society that devalues disability and cherishes, above all, development, independence and progress' (McKeever and Miller 2004: 1187). The way in which parents retain the personhood of their child involves them reconsidering their own values about family life and their own views and judgements about disability. Landsman argues that through this reconsideration mothers relate to their child as a 'gift', in this way the child plays an active role in the lives of the family, they are not just someone the mother must care for. In the process the mothers 'reinstate the personhood of their children and the full value of their own motherhood' (1999: 158).

3.5 Therefore, the presence of a disabled child within a family can become a 'turning point in the biography' (Chamberlayne and King 1997: 605) of their sense of self and identity as they rewrite their and their children's future. The children are participants in this; their presence in their family's lives changes them. The new set of relations and roles parents become part of not only changes their material life, it changes their sense of self and identity in ways which can be difficult, challenging (physically, financially and emotionally) and a source of conflict within the family. In seeking analytical frameworks for understanding how childhood disability changes the lives and identities of those involved it is important to examine care activities as fundamental to this process. 


\section{Methods}

4.1 The need to understand the perspective and experiences of parents with very young children is a central element of ongoing research this paper draws from. At this age the ability of children, whether disabled or not, to assert their own views on their needs is limited (although not non existent). Therefore, parents become the conduit between the care the children receive and the suppliers of that care. The research is centred on exploring, from the parents' perspective, what constitutes enabling care for them and for their children. The overall methodology is framed by ethnography and a wish to provide spaces within which the cultural, social and material practices and relationships that make up and inform their lives with their children can be explored. The research, which has now been underway for two years, is based in two English regions; at the centre of the fieldwork are 33 families who have been involved in the study for over eighteen months. Where there were two parents living together we interviewed both together if they wished, during these interviews important gender differences still appeared in the varied roles the parents appeared to adopt and how they understood and conceptualised their lives and the role of care within it. The parents were recruited from a variety of sources; in particular advertisements in support group newsletters, other forms of support group advertisement using information flyers, and contact via health and social care professionals ${ }^{[2]}$. Where a family came through a health or social care professional, the professional simply passed on the information flyer and never knew whether the parents contacted the project. When a parent did contact us, before signing consent, a researcher met with parents for an informal, pre participation meeting, which occurred in their home (as all subsequent interviews did). At these pre participation meetings, discussion was not tape recorded, nor subsequently used in the research.

4.2 The families are divided into two groups, the first group (fifteen families) have children up to eight years old who are around two to three years on from some form of diagnosis, the second group (eighteen families) are younger infants up to three years old who have received some form of diagnosis within the past year of initial contact. With the first group a series of three retrospective in-depth narrative interviews (tape recorded with consent) have been used to reflect back on their experiences from the birth of their child. With the second group of parents the time spent with them and the depth of engagement is of a deeper level. Over the eighteen month period a series of three narrative interviews (again tape recorded with consent) have been undertaken, one of the main objectives of the return interviews is to explore how things have changed for the parents over time, in particular how they think differently about their child, role, family and the relationships they have with the services and communities around them. The return interviews have been an invaluable way in which quite significant changes in how parents define themselves and their children, sometimes negatively, sometimes positively, have been captured. Interviews range in length; the majority of retrospective interviews took around one hour to ninety minutes each, the longitudinal interviews tended to take longer, on average two hours. All interviews have been transcribed, checked and sent back to parents; in return interviews the transcripts have been subsequently used as a starting point for discussion and reflection on change. With the second group of parents observations of a number of formal and informal care encounters, which situate the researcher within the context in which care operates and is experienced, have also taken place. Alongside the work with the parents mixed focus groups with professionals working in health, education, social care, and the voluntary sector have also occurred.

4.3 Analysis developed through a number of strategies. All interview and focus group transcripts and observation notes were entered into Nvivo, the software was used to link conceptual codes to fieldwork material (the first set of conceptual codes developed out of paper analysis of pilot interviews by the research team and further developed through discussion of subsequent fieldwork materials), codes were mapped, both through the different interviews and observations with each family to explore change, and also, across families and professionals to consider points of similarity and difference. Analysis of interviews across both sites also took place outside of Nvivo, through team discussion of fieldwork material and conceptual ideas developing from them. Observations notes were examined alongside interviews to explore lived experiences that exemplified the dynamics parents discussed in interviews. Focus group interviews were examined in contrast to parent observations and interviews to identify differences in professional and parental frameworks of understanding.

4.4 The discussion in this paper focuses on experiences and narratives that have emerged in one of the regions we are working in. The demographic information listed below relates to that region and the twelve families that constituted its research group. When recruiting the parents the deliberate step was taken not to recruit one form of childhood impairment or condition, as this seemed to fit within a medical approach. Instead the basis for a family's inclusion was that they defined their child as having specific care and support needs and that the child was within the age range used in the project. Through this means a range of conditions or impairments was obtained. Two children have a label of autistic spectrum disorder, two have one of Down's syndrome, one has a permanent tracheotomy, one has cerebral palsy, three have different forms of genetic condition, two have some form of brain damage and one has physical and learning impairments, which are linked to a problem during pregnancy. The parents come from a range of different 
locations and backgrounds that do not sit easily within fixed social classifications or translate easily into contributors to their lives and values. Of the twelve families, ten are a married or co-habiting heterosexual couple; the other two are single mothers. In five cases parents were interviewed together for most or all of the interviews. Therefore, the total number of respondents in this group is 17 , all of whom were interviewed three times; in addition a series of observations (in most cases three per family) took place with five of the families who constitute the longitudinal group. Through housing situation and employment status of the family members, eight of the families could be defined as working class and the others lower middle or middle class. There was a range of ethnicities within and between the different families, in two cases we worked with immigrants to the UK whose first language was not English; interpreters of the family's choosing were used during the interviews and translations of interview materials provided.

\section{Contained care}

5.1 Disability studies research has identified the ways in which formal care support fails both parents and children (Beresford 1994; Sloper, 1999). Families with young children with disabilities experience a variety of refusals to care and rejections from both formal actors and agencies. Through these refusals care is drawn inwards as a private, family matter where parents, in reality often the mother, are the central actors. The minimalist approach that parents find within formal care provision keeps care in the private sphere and articulates public responsibilities towards care as a burden on the state and society, which mothers should take responsibility for (Traustadottir 1991). However, while the material lack of care provision within the state system is important, what will be focused on here (in part because the lack of provision is already well documented by writers such as Beresford and Sloper) are the ways in which care practices are contained through the forms of medical care offered to children and through wider social ignorance regarding disability.

5.2 As well as documenting the structural and institutional failures of state care, disability studies has also conceptualised the institutional practices that pathologises disability and those diagnosed with impairments (Oliver 1996; Swain et.al. 1993). In particular the presence of the medical model of disability in health and social care professional discourses is criticised for narrowing care to the alleviation of the physical or developmental consequences of impairment. When the parents in the study talk about their professional encounters, particularly around diagnosis, it is clear that the medical model remains a defining template within which institutional provision of care is shaped and confined:

People like the GPs (laughs) they are the bain of my life with Harry because they don't see past his disability they just think well I don't know what they think but they don't investigate him when he's got problems properly... (Angela, mother of an 8 year old child with the label of autistic spectrum disorder. Second Interview)

5.3 Parents like Angela talk of the difficulty in getting professionals to see their child as something more than the condition being treated or diagnosed. Where it is the mother who is the primary carer, attending the medical appointments and visible with the child in the public sphere, it is she who bears the brunt of being confronted by medical constructions of her child (Gray 2002). Parents involved in the research have spoken in depth about how they experienced being on the end of a diagnosis and the implications for their child and themselves (Bogdan, Brown and Foster 1992). One couple spoke about the grief and sense of loss they experienced when told by a paediatrician that their child had Down's syndrome. The doctor had 'hit and run': leaving the scene as quickly as possible and appeared very uncomfortable around the subject, as if he were the bearer of the most profoundly distressing news. However, three years on, the fact their child has Down's syndrome is for them merely one element of who he is, and the condition itself has not meant the loss of his humanity. It took them some time to be able to appreciate this, time they felt stretched because of the disaster scenario suggested by the original consultant's manner.

5.4 Professionals are keen to talk about the stages of grief that parents move through, parents too acknowledge feelings of grief as they care for their new baby. However, it is important to question the sources of grief. For the parents in the study their grief is narrated within a context of lack of care for them and their child, where services expect and ultimately demand that they will be the carers and managers of their child, again a responsibility targeted towards the mothers:

And it's just trying to get, to understand people how, kind of damaged and devastated you are as a person when this happens, but then the expectation that you'll suddenly become superwoman or super-dad, and take on physiotherapy, [laughs] thousands of hospital appointments, and do all of this stuff as well as that, it just doesn't, it's an equation that just doesn't work. (Kay, a mother of a 3 year old child with learning and physical impairments. First Interview)

5.5 One aspect of the responsibility the parents experience, and one again mothers often carry the greatest role within, is the requirement to explain their child and their difference to others. From the point where the 
child is diagnosed with a condition or begins to display behaviours or symptoms outside of the norm, explanation is required and the normal narrative of mothering and the rituals and codes around it disappear (Landsman 2000). Through the act of 'having' to explain the family becomes framed as different, as unusual, in the same way that heterosexuality does not need to be explained, the parents realise that their child is now in a social category that will always be required - by others - to be explained: 'And you think it's just something that happened, and you've got to start explaining and you think, I don't want to explain my child, you don't have to explain your child' (Jemma and Richard, parents of a baby with a rare genetic condition. First Interview).

5.6 Having to explain emerges out of the discomfort others feel in the presence of disability, what several of the families in the study grieve is the loss of family and friends who quickly withdraw after the birth or diagnosis of their child, in the process limiting the wider care that could be provided for them. Prejudice and discomfort with disability frames much of their accounts about why people withdraw from them. Friends and family who could provide care and support for the child and the parents instead marginalise the family into the status of stranger and other, uncomfortable with what the family now represent in their altered form of life outside of nuclear family tales of normalcy. This rejection of support and friendship is particularly marked where the child has been labelled with learning disabilities such as autistic spectrum disorder. One mother described how her family's social world had shrunk since their child had received the diagnosis. Time again extended family members failed to appreciate the needs of the child and the parents, and instead made sweeping presumptions based on stereotypes and ignorance:

I see my family as being like me, John, Jack and Laura. And they're the, they're the ones who are the most important... You know John's brother turned round when he said, 'I'm, really, you know, l'm not coping, you know like since Jack got diagnosed.' And he said, 'Well, what's your problem?' he said, 'all autistic people'll end up being mathematicians; they're really good with numbers.' Em, my brother had a birthday party for his daughter in July, and I'm supposed to be her godmother, but they didn't invite us along and I think it's because of Jack's condition because they don't like it. So we've just said, right that's it... (Jane, mother of a 5 year old with the label of autistic spectrum disorder. First Interview)

5.7 Within medical care encounters medical understandings of disability help to frame the child and the family as different; they also contribute to the channelling of caring responsibility (including the responsibility to explain) towards the mother. Within the community and family networks the families also experience an inability to care amongst many of those closest to them; this lack of care is informed by the lack of value placed on their lives due to cultural norms about disability that place them, in particular their child, into the social category of other and lesser. However, over time, parents are not passive in response to these failures to care amongst either state or community actors. Instead they strive to find meaning and identity for the lives they lead. What is significant is that this process is not a private, insular one, it occurs via and within links to caring networks which respect and value the lives the families lead and the future possibilities that are available to them.

\section{Embedding impairment}

6.1 Parents actively seek to develop contexts where their children are recognised as human beings rather than containers of various conditions. Parents talk of the need to get away from medical care (however beneficial it has been) and professionals (however supportive they have been) in order to regain their child and develop new templates for their family life and broader versions of care. Therefore, parents seek to retain a physical and emotional distance between themselves, their child and the medical care he or she receives to ensure the condition or label does not come to define their child and the relationships they are all part of (Place 2000). As a result parents sometimes make decisions that may seem counter intuitive to professionals. For example, one mother (who was herself a trained nurse) asked for her child to remain in hospital when receiving complicated medical care, rather than coming home:

It's like, we, we didn't want, we knew what was normal, for us 'normal' was the low levels of oxygen, where as Frank was on high levels of oxygen. It gets to the point where you have got too many things to think about, and it's, I couldn't do it, we didn't want to do it... I didn't, didn't want to have to think about it... it's then not normal... it's then a medical problem and somebody else will have to deal with it. (Debbie, a mother with a 2 year old child with a permanent tracheotomy. First Interview)

Others might interpret this mother as refusing her 'natural responsibility' to her child by refusing to take the child home, instead for Debbie what she was refusing to do was turn her home and family into a medical venue. 
process of narrative adjustment to reframe their lives and futures. Over time the families in the research talk about how their lives become normal, perhaps not normal for others, but normal and everyday for them:

I'm just so used to it now (laughs) sometimes I don't bother explaining, I just think oh well if they think we're a weird family they think we're a weird family, who gives a monkey it's their problem not mine... (Angela, mother of an 8 year old child with the label of autistic spectrum. Second Interview)

A process of embedding impairment into family life is occurring here, as families move away from medical models that understand their lives as a tragedy and away from social norms of the perfect family life. The day to day, at times intensive, caring activities that are part of, and at times structure, family living, take on an 'ordinariness' that sits outside discourses of tragedy or heroism, in order to value the child as a full and equal member of the family. This process is most marked amongst the families with older children, who often, while still receiving medical and social care support, are less likely to be involved in the medically intensive context of diagnosis and hospital care.

6.3 One aspect of embedding impairment is refusing to explain, to justify their child's behaviour to others. As discussed earlier, the parents whose young children have the label of autistic spectrum disorder talk of often having to explain the behaviour of their children, which others define as disruptive in public spaces (within this also is often an implicit or explicit judgement of the parent as a bad mother or father for not controlling their child). However, as the parents increasingly see their child and the impairment as 'normal,' they feel fewer obligations to others to explain their child and justify they own parenting practice. For Angela supermarkets are always a challenge as her son often acts in ways others read as naughty. She recognises the judgements being made of her within that reading; however she refuses now to acquiesce to this by explaining her son:

Well half the time now, I just think, oh I can't be bothered to explain, I told you about the time when he ate the French stick [in a man's shopping trolley].... He probably thought he was on Jeremy Beadle or something (laughs). (Angela, mother of an 8 year old child with the label of autistic spectrum disorder. Second Interview)

\section{Political caring}

7.1 The families' lives and values are transforming via their caring activities and the embedding of impairment into their family form. What is significant is that these processes of transformation are not internal; they are informed by and articulated within political and collective discourses and locations.

7.2 In walking away from the contexts that imprison their lives as abnormal and tragic families draw on, explicitly or inexplicitly, disability movement arguments. Families change how they think about disability and the constraints society places on those with impairments. They open up their caring response and role to others they recognise as marginalised by societal refusal to respect, acknowledge and care for. Acknowledging that children with impairments are still of value and worthy of care does not mean they no longer wish that their child did not have the condition they have (the paradox explored by Larson (1998)). Instead they are able to look beyond social rejection of impairment and production of disability by promoting care not just for their children but for other children with impairments to:
... You know it's the same when you, some of these kids have got no hair you know, even, I would never have dreamt of going up to one of them and going, 'ooohh it's nice and soft', but I've done that now because I know some of them well enough to, you know say, ooh your head is lovely with no hair. And they don't mind. But somebody in the street would be like, 'aahh, you can't say that!' but you can because they're normal, you know, that, I think that's the biggest thing l've learnt, you know just to accept... And so this is the cards l've been dealt with, you've just got to get on with it. I can't change it unfortunately. If I could I would. If I would change it, you know if somebody said you can chop your arm off and make him right, I would chop my arm off. I would give anything, anything. [Pause] like I say I think we deal alright with it. (Jemma and Richard, parents of a baby with a rare genetic condition. Second Interview)

7.3 Several of the parents who we are working with who have been battling with services for some time talk of how they have changed, and how their sense of self has altered in ways they never expected. These transitions were discussed most acutely by the mothers in the study. The mothers find new meaning and senses of self in their caring role, in particular fighting injustice against their children and others becomes an important part of what they define as the caring role and is embedded in their identity: 
pushing... and I think getting out there and finding out the information for yourself and finding out your rights and your wrongs and talking to other parents who've been through similar things before you, and that's definitely helped. (Angela, mother of an 8 year old child with the label of autistic spectrum disorder. First Interview)

7.4 Such changes are not confined to women from educated, middle class backgrounds; in a way the most acute transformations and desires to challenge what others 'offer' for the child come from mothers (such as Angela) from relatively under privileged backgrounds, who refuse to be grateful for what is provided for them and their child. Such mothers challenge both the gendered and classed discourses that assume they are unable to articulate the care needs of their child.

7.5 In defining their caring role, the mothers include their battles with statutory services on behalf of their child. As one mother who is a new immigrant to the UK asserted strongly 'but as like a normal person, his rights need to be respected as well, as the rights of a normal person are respected' (Corinne, mother of a 2 year old child with brain damage. First Interview). Mothers speak proudly of their strategies for getting what they can for their child; therefore their caring role is not perceived as a private role, it sits in the public realm of the care plan meeting and the statementing process ${ }^{[3]}$.

\section{Caring networks}

8.1 Families are transformed, not as nuclear family units, but through the development of new communities of friendship and connection that replace the loss of friends and family unwilling to recognise their new lives and value systems.

...we met this family at Perth the other week whose little girl has like the same eye condition. We now know Sue, and I said to Richard, 'isn't it funny how our circle of friends has now shifted'? It's people, I mean some of them, like I say they're you know fantastic, we've still got the same friends but a lot of our new friends are friends that we've met like Amy and Colin with Thomas, in the same situation as us. And our friendship tends to be at a different level now. It's not you know, the going out and having drinks, it's just the phoning up and the support that we get off each other. (Jemma and Richard, parents of a baby with a rare genetic condition. First Interview)

8.2 What different friendships with other families who have disabled children offer is a space and caring appreciation that is without judgement and the need for explanation; where their new normality is appreciated, celebrated and cared for. The children within the families they make new friendships with sometimes have the same condition as their child, but not always. Support groups that are not condition specific are important in providing public spaces within which families can interact with others in similar positions, not due to their child's condition, but through the social exclusion generated through the disvaluing of their lives and child. A local generic support group run a cinema event every few months where a multiplex cinema is booked out for families to come and watch films. One mother spoke of the value she found in coming along to these events.

... it was lovely 'cos it was just, they'd booked out two halls and there was one with em, like
subtitles, and there was another one, and they had obviously like disabled sitting areas... I
don't know if you know him, Mark who runs that, em, he just came in and he says, 'Oh,' you
know he says, 'the last time we had something like this,' he goes, 'all you could hear all the
way through the film was the parents goin' shh, shh. Don't do this, don't do th',' and he goes,
'if any of y's get told to like be quiet, or shh, or anything like that,' he goes, 'you've got to tell
me straight away and I'm gonna pull your parents out.' (laughs)... Jack ended up, he sat
beside us, then he was slouching, he went to the toilet four times in an hour... and I just
thought, oh, just let him do it. But I couldn't have done that normally, because I would've had
somebody behind us goin', 'Look what that kid's doing. She's just letting him do that.' (Jane,
mother of a 5 year old child with the label of autistic spectrum disorder. First Interview)

The opportunity to be a mother with her child, without having to explain him in order to be accepted and still cared for, is valued. The events are a form of care, of invitation to be part of public space, on their terms. It is not a replacement for being able to go the cinema or the supermarket without social judgements being made, but it offers a public space within which recognition is given to new family forms, without either being read as heroic or tragic. It is a form of public care, which recognises that the families support each other and that others have a role to play in caring for the children and their intimate families.

\section{Conclusion}

9.1 When a child is diagnosed with a long term condition or impairment it is not only the child who 
becomes the other, it is the family as a whole; the introduction of impairment into the family changes the bourgeois story of the private nuclear family life. The narrative that what lies ahead is raising children to become successful independent adults, making their contribution to society through work and raising their own family is destabilised. In response parents seek new forms of normality for their children and their own life. A significant element of this is embedding impairment into their lives as part of the everyday. What makes embedding impairment difficult is the wider social contexts that produce disability as tragedy and other; is the material constraints that envelope their lives; is the marginalisation and privatisation of care as a mothers' responsibility, which denies the role of wider society in the provision of care; is the bureaucratic structures of state care that work within pathological models of disability. Where care provision is presented as individualistic, as focused only on the 'condition' rather than the child, as a form of charity and private responsibility rather than public right and entitlement, families remain locked in marginalised positions that construct them as 'troubling' to society and enforce the caring role on the mother.

9.2 Transformative care activities engage with re-evaluation of identity, the future, family templates and biographies, and political and ethical values. In becoming carers, parents, along with their children, move through transitions which ultimately broaden care to encompass political dimensions which, through collective friendships and bonds, mean that parents actively seek to incorporate political values and activities into the caring role they embed in their lives and their identities. Care activities sit within a political discourse able to challenge rights discrepancies and to identify the child and family as full members of society.

9.3 These processes of transition for the family are influenced by social conditions and values. Mothers remain, through gendered expectations about caring roles, at the forefront of medical and societal judgements about their children. It is important that disability studies and the disability movement recognises the political agency mothers adopt in challenging such judgements, through their refusal to explain, and their wish to challenge what is 'offered' for their child. At the same time, drawing from feminist arguments, we also need to acknowledge the costs of the role for women and those they are in caring relationships with. For women, there is the loss of role and identity they have over and above being a carer, for example mother, friend, colleague; various aspects of identity can become subsumed by being a carer. The presumption that mothers are the primary carers of disabled children robs the children of varied care interactions with others and a fuller family and social life.

9.4 Disability studies is enhanced by exploring the experiences of parents who care for disabled children, as the work on mothering disabled children is beginning to show. By capturing the difficulties parents, in particular mothers, face in the refusal by others to care for them as well as their children, what is being captured is the social exclusion of people (parents and children) who experience disability. Capturing the processes that confine women as the primary carers does not need to occur in a way that excludes those being cared for from the discussion. It is not to the benefit of disabled children to assume that the responsibility for care lies with the mother. Mothers, and at times fathers, are important political actors who challenge, through their care activities, the privitisation and marginalisation of care for disabled children. Exploring the transformations, which occur for them through the intensive caring relationships they have with their children allows for appreciation of the injustices embedded in societal and medical judgements about disability and the political importance of placing care within a rights model of inclusion and recognition for the family as a whole.

\section{Notes}

1'Parents, Professionals and Disabled Babies: Identifying Enabling Care (RES-000-23-0129)'

(http://www.shef.ac.uk/inclusive-education/disabledbabies/). The other people involved in the project are Dr Emma Clavering (University of Newcastle), Dr Dan Goodley (University of Sheffield) and Dr Pamela Fisher (University of Sheffield). I would like to take the opportunity to thank them for their involvement in the development of this paper and their comments on earlier drafts. In particular, Emma Clavering who has done much of the fieldwork discussed here.

${ }^{2} \mathrm{NHS}$ Research Ethics Committee approval was granted in both our localities.

${ }^{3}$ The care plan meeting is where local social services define the support needs of the child and family and what they will do to meet those needs. Parents often challenge care plans in order to secure more resources and support for the family. The statementing process is the means through which the child is defined as having special educational needs which the school must then provide for (and can seek funding to help support). Parents often push for their child to obtain a statement of special educational needs, however the process is a complex and difficult one that has within it issues around the construction of disability and segregation. 


\section{References}

BARNES, C. (1998) 'The Social Model of Disability: A Sociological Phenomenon Ignored by Sociologists'? In T. Shakespeare (editor) The Disability Reader: Social Sciences Perspectives. London: Cassell.

BERESFORD, B. (1994) Positively Parents: Caring for a Severely Disabled Child . London: HMSO.

BERESFORD, B., SLOPER, P., BALDWIN, S. and NEWMAN, T. (1996) 'What Works in Services for Families with a Disabled Child?' Ilford: Barnado's.

BOGDAN, R., BROWN, M. A. and FOSTER, S. B., (1992) 'Be Honest but not Cruel: Staff/parent Communication on a Neonatal Unit' In P. M. Ferguson, D. L. Ferguson and S. J. Taylor (editors) Interpreting Disability: A Qualitative Reader. New York: Teachers College Press.

BRETT, J. (2002) 'The Experience of Disability from the Perspective of Parents of Children with Profound Impairment: Is it Time for an Alternative Model of Disability', Disability \& Society, 17 (7), pp: 825-843.

CHAMBERLAYNE, P. and KING, A. (1997) 'The Biographical Challenge of Caring', Sociology of Health \& IIIness, 19, pp. 601-621.

DALE, N. (1996) Working with Families of Children with Special Needs: Partnership in Practice . London: Routledge.

DEELEY, S. (2000) 'Professional Ideology and Learning Disability: An Analysis of Internal Conflict', Disability and Society, 17, pp 19-33.

DOBSON, B., MIDDLETON, S. and BEARDSWORTH, A. (2001) The Impact of Childhood Disability on Family Life. York: YPS.

FINCH, J. and GROVES, D. (editors) (1983) A Labour of Love: Women, Work, and Caring . London: Routledge \& Kegan Paul Ltd.

FINKELSTEIN, V. (1996) 'Outside 'Inside Out”, Coalition, April, pp 30-36.

GILLIGAN, C. (1993) In a Different Voice. London: Harvard University Press.

GRAY, D. E. (2002) "Everybody Just Freezes. Everybody Is Just Embarrassed': Felt and Enacted Stigma among Parents of Children with High Functioning Autism', Sociology of Health \& IIIness , 24 (6), pp: 734749.

GREEN, S. E. (2003) "'What Do You Mean 'What's Wrong with Her?"': Stigma and the Lives of Families of Children with Disabilities', Social Science \& Medicine, 57, pp: 1361-1374.

HARRIS, J. (2003) Ostrich Politics: Exploring the Place of Social Care in Disability Studies. Keynote paper at Disability Studies: Theory, Policy and Practice Conference, Lancaster, September.

HAYS, S. (1996) The Cultural Contradictions of Motherhood. New Haven and London: Yale University Press.

HUGHES, B. (1999) 'The Constitution of Impairment: Modernity and the Aesthetic of Oppression', Disability \& Society, 14, pp 155-172.

HUGHES, B. (2002) 'Bauman's Strangers: Impairment and the Invalidation of Disabled People in Modern and Post-Modern Cultures'. Disability \& Society, 17, pp 571-584.

JAMES, A. (1993) Childhood Identities, Self and Social Relationships in the Experience of the Child . Edinburgh: Edinburgh University Press.

KELLY, S. E. (2005) "'a Different Light" - Examining, Impairment through Parent Narratives of Childhood Disability', Journal of Contemporary Ethnography , 34 (2), pp: 180-205.

KITTAY, E.F. (2002) 'When Caring is Just and Justice is Caring: Justice and Mental Retardation' in E.F. Kittay, and E.K. Feder, (editors) The Subject of Care: Feminist Perspectives on Dependency. Oxford: Rowan and Littlefield Publishers.

LANDSMAN, G. (1999) 'Does God Give Special Kids to Special Parents: Personhood and the Child with 
Disabilities as Gift and as Giver' in L.L. Layne, (editor) Transformative Motherhood: On Giving and Getting in a Consumer Culture. New York and London: New York University Press.

LANDSMAN, G. (2000) "'Real Motherhood," Class, and Children with Disabilities' in H. Ragone, and F.W. Twine, (editors) Ideologies and Technologies of Motherhood: Race, Class, Sexuality, Nationalism. New York: Routledge.

LANDSMAN, G. (2003) 'Emplotting Children's Lives: Developmental Delay Vs. Disability', Social Science \& Medicine, 56 (9), pp: 1947-1960.

LARSON, E. (1998) 'Reframing the Meaning of Disability to Families: The Embrace of Paradox', Social Science \& Medicine, 47, pp: 865-875.

LINDEMANN, K. (2003) 'The Ethics of Receiving', Theoretical Medicine, 24, pp 501-509.

LISTER, R. (1999) 'Citizenship and the Ethics of Care', Policy and Politics , 27, pp

233-246.

MCKEEVER, P. and MILLER, K. L. (2004) 'Mothering Children Who Have Disabilities: A Bourdieusian Interpretation of Maternal Practices', Social Science \& Medicine, 59 (6), pp: 1177-1191.

MORRIS, J. (editor) (1996) Encounters with Strangers: Feminism and Disability. London: The Women's Press.

MURRAY, P., and PENMAN, J. (editors) (2000) Reflections on Disabled Family Life. Sheffield: Parents with Attitude.

OLIVER, M. (1996) Understanding Disability. Basingstoke: Macmillan.

PLACE, B. (2000) 'Constructing the Bodies of Critically III Children: An Ethnography of Intensive Care' in A. Prout, (editor) The Body, Childhood and Society. Basingstoke: Palgrave.

PROUT, A., et al. (1999) 'Medicines and the Maintenance of Ordinariness in the Household Management of Childhood Asthma', Sociology of Health \& IIIness , 21 (2), pp: 137-162.

SAFILIOS-ROTHSCHILD, C. (1970) The Sociology and Social Psychology of Disability and Rehabilitation . New York: Random House.

SEVENHUIJSEN, S. (1998) Citizenship and The Ethics of Care. London: Routledge.

SHELDON, A. (1999) 'Personal and Perplexing: Feminist Disability Politics Evaluated', Disability \& Society, 14 , pp $643-658$.

SLOPER, P. (1999) 'Models of Service Support for Parents of Disabled Children. What do we know? What do we need to know'? Child: Care, Health and Development, 25 (2), pp.85-99.

SKEGGS, B. (1997) Formations of Class and Gender . London: Sage.

SWAIN, J., FINKELSTEIN, V., FRENCH, S. and OLIVER, M. (editors) (1993) Disabling Barriers - Enabling Environments, London: Sage.

TRAUSTADOTTIR, R. (1991) 'Mothers Who Care: Gender, Disability and Family Life', Journal of Family Issues, 12 (2), pp: 221-228.

WATSON, N., MCKIE, L., HUGHES, B., HOPKINS, D. and GREGORY, S. (2004) '(Inter)Dependence, Needs and Care: The Potential for Disability and Feminist Theorists to Develop an Emancipatory Model', Sociology, 38, pp 331-35. 